\title{
Atividade antibacteriana e cicatrizante do óleo de buriti Mauritia flexuosa $\mathrm{L}$.
}

\author{
Antibacterial and healing activities of buriti oil Mauritia flexuosa L.
}

\author{
Jael Soares Batista ${ }^{I^{*}}$ Roberio Gomes Olinda $^{\mathrm{I}}$ Vitor Brasil Medeiros $^{\mathrm{I}}$ \\ Carla Monadeli Filgueira Rodrigues ${ }^{I}$ Andréia Freitas Oliveira ${ }^{I}$ Erika Souza Paiva ${ }^{I}$ \\ Carlos Iberê Alves Freitas ${ }^{I}$ Aldo da Cunha Medeiros ${ }^{I I}$
}

\section{RESUMO}

\begin{abstract}
O objetivo deste estudo foi avaliar a atividade antibacteriana in vitro e cicatrizante do óleo de buriti (M. flexuosa) em feridas realizadas em ratos (Rattus norvegicus albinus). Para a avaliação antibacteriana in vitro, foram utilizados cinco patógenos bacterianos incluindo espécies grampositivas e espécies gram-negativas mediante o uso do método de difusão em ágar. Para a avaliação da atividade cicatrizante, foram utilizados 40 ratos da linhagem Wistar, divididos em dois grupos: o grupo I, composto por 20 ratos com feridas cutâneas, tratados com aplicação tópica do creme base com $10 \%$ de óleo de buriti, e o grupo II, controle, com o mesmo número de animais que receberam a aplicação tópica do creme base. A aplicação do produto foi realizada em feridas padronizadas, circulares de $1 \mathrm{~cm}$ de diâmetro na região dorsolombar. As avaliações clínica, morfométrica $e$ histopatológica das feridas foram realizadas no $3 \frac{0}{2} 7^{\circ}, 14^{\circ} e$ $21^{\circ}$ dias. Em relação à avaliação da atividade antibacteriana, os resultados mostraram que houve inibição do crescimento bacteriano em quatro dos cinco patógenos testados. Em relação à área da ferida, foi observada redução significativa da área no $14^{\circ}$ dia e maior percentual de contração das feridas do grupo tratado em relação ao controle. No décimo quarto dia, as feridas tratadas com o óleo do buriti apresentavam aumento significativo na contagem de fibroblastos e fibras colágenas, além de completo processo de reepitelização, enquanto o grupo controle necessitava de mais tempo para resolução do processo cicatricial.
\end{abstract}

Palavras-chave: ação antibacteriana, processo cicatricial, ferida, óleo de buriti, M. flexuosa.

\section{ABSTRACT}

The aim of this study was to evaluate the in vitro antimicrobial activity and wound healing effect of buriti oil
(M. flexuosa) in rats. To evaluate the in vitro antimicrobial activity, five species of bacteria, including both gram-negative and gram-positive, were tested by the agar diffusion method. To assess the wound healing effect, 40 rats of Wistar lineage were clustered into two groups: G1, composed by 20 rats with cutaneous wounds and treated using topic administration of basic cream containing 10\% of buriti oil; and G2 or control group, composed by 20 rats with cutaneous wounds and treated using topic administration of basic cream without any buriti oil. The cream administration was performed on circular wounds of $1 \mathrm{~cm}$ area in the lumbodorsal region. Clinical, histopathologic and morphometric evaluations of the wounds were done in $3^{\text {rd }}, 7^{\text {th }}, 14^{\text {th }}$ and $21^{\text {th }}$ days. Four from five bacteria species tested had growing inhibition, which demonstrates the antimicrobial potential of buriti oil. A significant reduction on the wound area with contraction of the edges was found for G1 in the $14^{\text {th }}$ day. On this same day, the wounds treated using buriti oil showed an increase in the fibroblasts and collagen fibers countings and complete reephitelialization, characteristics not demonstrated by $G 2$.

Key words: antimicrobial action, healing process, wound, buriti oil, M. flexuosa.

\section{INTRODUÇÃO}

O buriti (Mauritia flexuosa), também conhecido como coqueiro-buriti, miriti, muriti, muritim, palmeira-dos-brejos, carandá-guaçu e carnadaí-guaçu, é uma palmeira da família Palmae, que vegeta as regiões alagadas e úmidas do Centro-Oeste, Norte e Nordeste do Brasil (ALMEIDA et al., 1998). O óleo extraído da polpa dos frutos de buriti desperta interesse devido à

'Departamento de Ciências Animais, Universidade Federal Rural do Semi-Árido (UFERSA), BR 110, Km 47, 59625-900, Mossoró, RN, Brasil. E-mail: jaelsoares@hotmail.com.*Autor para correspondência.

IICentro de Ciências da Saúde, Universidade Federal do Rio Grande do Norte (UFRN), Petrópolis, Natal, RN. 
sua composição química e farmacológica (SILVEIRA et al., 2005). Rico em carotenóides, ácidos graxos e tocoferol, o que sugere boa perspectiva na utilização desse produto como alternativa terapêutica e cosmética (ROSSO \& MERCADANTE, 2007), o óleo de buriti tem a função de lubrificar e regenerar a barreira hidrolipídica da pele frequentemente submetida a lesões (ZANATA et al., 2008). Também quando usado em produtos póssol, o óleo de buriti evita danos provocados por radiação UV, justamente por apresentar propriedades fotoprotetoras (ZANATTA et al., 2010).

Diversos fármacos obtidos a partir de plantas medicinais são usados como anti-inflamatórios e cicatrizantes. Paradoxalmente, apesar do uso cada vez mais frequente, elas têm o uso baseado apenas em conhecimentos populares, faltando o suporte de evidências experimentais que comprovem o potencial terapêutico, mecanismo de ação, toxicidade e os possíveis efeitos colaterais (VIEIRA et al., 2008).

O potencial terapêutico atribuído ao buriti abre perspectiva no sentido de utilizá-lo como fitoterápico, no entanto, há escassez de estudos que atestem a real atividade do seu óleo. Dessa forma, o presente estudo teve como objetivos avaliar a atividade antibacteriana in vitro e cicatrizante do óleo de buriti (M. flexuosa) em feridas realizadas em ratos (Rattus norvegicus albinus).

\section{MATERIAL E MÉTODOS}

Obtenção do material botânico

Os frutos do buriti, dos quais foi extraído o óleo utilizado no presente estudo, foram coletados após queda natural, no município de Timon, Maranhão, em dezembro de 2010. Em seguida, foi feita a classificação taxonômica da árvore, realizada através da identificação de suas folhas, flores e frutos no Herbarium Dardano de Andrade Lima, da Universidade Federal Rural do Semiárido (UFERSA), com registro noㅜ 11.565.

\section{Extração do óleo essencial de buriti}

Os frutos de buriti foram lavados em água corrente, submersos em solução de hipoclorito de sódio a $50 \mathrm{mg} \mathrm{kg}^{-1}$ por cinco minutos e, após esse período, os frutos foram despolpados manualmente com faca de aço inoxidável, cortados em lascas de $0,3 \mathrm{~cm}$ de espessura, $1,6 \mathrm{~cm}$ de largura e $2,8 \mathrm{~cm}$ de comprimento. A polpa de buriti foi seca em estufa com circulação de ar e, em seguida, o material foi triturado em multiprocessador Britânia por um minuto, sendo as amostras da polpa submetidas à extração do óleo, utilizando-se a metodologia de Soxhlet com emprego de hexano como solvente (reagente PA), no período de 4 horas de extração.
Avaliação da atividade antibacteriana in vitro do óleo de buriti

As cepas bacterianas utilizadas foram: Bacillus subtilis ATCC 6633, Enterobacter aerogenes ATCC 1304, Escherichia coli ATCC 25922, Klebsiella pneumoniae ATCC 10031 e Staphylococcus aureus ATCC 6538, semeadas em ágar BHI (Brain Heart Infusion) e incubadas em estufa bacteriológica à temperatura de $37^{\circ}$ por 24 horas.

Os ensaios das avaliações antibacterianas foram realizados em triplicata, através do método de difusão em ágar utilizando-se discos de papel filtro (Whatman, tipo 3) de 6,0mm de diâmetro, em placas de Petri contendo 20mL depositados sobre ágar MuellerHinton. Os inóculos foram obtidos a partir de culturas recentes dos microrganismos $\left(18-24 \mathrm{~h}\right.$ a $\left.37^{\circ} \mathrm{C}\right)$, preparando-se suspensões padronizadas através da escala 0,5 de MacFarland, que equivale a $1,5 \times 10^{8} \mathrm{UFC}$ $\mathrm{mL}^{-1}$ (PELISSARI et al., 2010).

O óleo proveniente do fruto do buriti ( $\boldsymbol{M}$. flexuosa) rendeu a concentração de $800 \mathrm{mg} / \mathrm{mL}$. A partir dessa solução, foram realizadas diluições em Tween 80 a $1 \%$, até obter as concentrações de $25 \mathrm{mg} \mathrm{mL}^{-1}, 12,5 \mathrm{mg}$ $\mathrm{mL}^{-1}, 6,25 \mathrm{mg} \mathrm{mL}^{-1}, 3,125 \mathrm{mg} \mathrm{mL}^{-1}, 1,5625 \mathrm{mg} \mathrm{mL}^{-1} \mathrm{e}$ $0,78125 \mathrm{mg} \mathrm{mL}^{-1}$. Cada concentração foi colocada em alíquotas de $5 \mu \mathrm{L}$ nos discos de papel filtro. No controle positivo, foi utilizado gentamicina na concentração de $10 \mu \mathrm{g}$, e no negativo o Tween 80 a $1 \%$ com solução salina $0,85 \%$. As placas foram incubadas a $37^{\circ} \mathrm{C}$ por $24 \mathrm{~h}$ em estufa bacteriológica. Os resultados foram obtidos através da mensuração do diâmetro dos halos de inibição de acordo a metodologia descrita por LIMA et al. (2006).

Formulação do creme

Ao creme base, constituído de água 34,5\%, glicerina $6,0 \%$, álcool cetoestearílico $5,0 \%$, mono estearato de glicerina $3,0 \%$, lauril éster sulfato de sódio $1,5 \%$, foram adicionados $10 \%$ de óleo extraído do buriti em cada $100 \mathrm{~g}$.

Animais utilizados e procedimento cirúrgico

Foram utilizados 40 ratos (Rattus norvegicus albinus) da linhagem Wistar, machos, com 60 dias de idade, pesando aproximadamente 120 gramas, acondicionados em gaiolas de propilpropileno, em condições de temperatura e umidade ambientais, alimentados com ração comercial (Labina Purina) e água à vontade.

Os animais foram divididos em dois grupos: o grupo I foi composto por 20 ratos com feridas cutâneas, tratados com aplicação tópica do creme base com $10 \%$ de óleo de buriti, e o grupo II, controle, com o 
mesmo número de animais que receberam a aplicação tópica do creme base sem o óleo de buriti.

Para a realização das feridas cutâneas, os animais foram anestesiados através da técnica dissociativa utilizando cloridrato de xilazina $\left(10 \mathrm{mg} \mathrm{kg}^{-1}\right)$ e cloridrato de cetamina $\left(50 \mathrm{mg} \mathrm{kg}^{-1}\right)$, administrado por via intramuscular. Após anestesia, foram feitas tricotomia e anti-sepsia do local cirúrgico com álcool iodado a $2 \%$. Uma lesão circular de $1 \mathrm{~cm}$ de diâmetro foi realizada na pele da região dorsolombar. O creme foi aplicado imediatamente após cirurgia e, posteriormente, duas vezes ao dia durante 21 dias com auxílio de espátulas de madeira estéreis e individuais.

Análise morfométrica das lesões

As lesões foram medidas em seu diâmetro maior e menor, empregando-se paquímetro, no dia 0 (dia de produção das lesões cutâneas) e nos dias 3ㅜㅜ 7을 14ํ e 21ํ pós-operatório. Para calcular a área das feridas, utilizou-se a equação formulada por PRATA et al. (1988). O grau de contração expresso em percentual foi mensurado pela equação proposta por RAMSEY et al. (1995).

Avaliação morfológica das lesões

Concomitante à mensuração da área da lesão, realizou-se a eutanásia dos ratos com dose inalatória letal de éter etílico em recipiente fechado. Fragmentos de tecidos foram fixados em formalina a $10 \%$ e submetidos à inclusão em parafina, para obtenção de cortes de $5 \mu \mathrm{m}$ de espessura, corados pelo método de hematoxilina-eosina (HE).

Para avaliação microscópica da evolução da cicatrização, utilizou-se o estudo histopatológico dos cortes corados ao HE. Empregando-se um sistema digitalizador e analisador, as imagens foram capturadas por câmera Canon e digitalizadas por computador através de Software Image Pro-plus, versão 6.0 (Media Cybernetics - LP, USA). Os cortes histológicos foram examinados para quantificação de polimorfonucleares, macrófagos, vasos sanguíneos, fibroblastos e fibras colágenas.

\section{Análise estatística}

Os resultados de área e contração das feridas foram expressos em média \pm desvio padrão, sendo submetidos à análise de variância e ao teste de Duncan, considerando-se significativo ao nível de 5\% de significância. Para as variáveis quantitativas, empregou-se o teste estatístico t de Student para verificar se houve diferença entre os resultados encontrados no grupo controle, quando comparados com o tratado com buriti. O nível de significância estabelecido foi de 5\%, ou seja, $\mathrm{P}$-valor $<0,05$ considerase estatisticamente significante.

\section{RESULTADOS E DISCUSSÃO}

Os ensaios de atividade antibacteriana in vitro mostraram que o óleo do buriti (M. flexuosa) evidenciou inibição de quatro dos microrganismos avaliados: E. aerogenes ATCC 1304, B. subtilis ATCC 6633, K. pneumoniae ATCC 10031 e $S$. aureus ATCC 6538. Os halos de inibição de crescimento bacteriano foram 8,7mm para E. aerogenes ATCC 1304, 16,5mm para B. subtilis ATCC 6633, 15,0mm para $K$. pneumoniae ATCC 10031 e 11,1mm paraS. aureus ATCC6538(Tabela 1).

Com base no diâmetro dos halos de inibição, pôde-se constatar que o B. subtilis, $K$. pneumoniae e o $S$. aureus evidenciaram maior sensibilidade ao óleo do buriti (Tabela 1).

A atividade antibacteriana de produtos de origem vegetal é mais intensa sobre bactérias grampositivas do que sobre gram-negativas, fato aqui também constatado, com a exceção da espécie $\boldsymbol{E}$. coli, em que não houve inibição da atividade bacteriana. Parte-se do pressuposto de que essa característica está relacionada aos constituintes fitoquímicos presentes no óleo vegetal, visto que não apresentou atividade inibitória para esse gênero bacteriano, provavelmente isso ocorreu devido as peculiaridades da conformação estrutural da parede celular dessa bactéria (OLIVEIRA et al., 2007). Tal fenômeno pode ser explicado porque a membrana externa das bactérias gram-negativas pode representar uma barreira contra substâncias ativas presentes nos extratos e óleos oriundos de plantas medicinais (URZUA et al., 1998). No entanto, neste estudo, o óleo do buriti mostrou atividade tanto em cepas gram-positivas quanto em gram-negativas, sugerindo atividade inibitória de amplo espectro.

Ao exame macroscópico, no terceiro dia pósoperatório, as feridas dos animais pertencentes ao grupo I apresentaram leve hiperemia e estágio inicial da formação das crostas, enquanto que os animais pertencentes ao grupo controle apresentavam lesões com acentuada hiperemia e com bordos edemaciados. No sétimo dia pós-operatório, as feridas tratadas com óleo de buriti apresentavam uma fina crosta nivelada com a pele e sem evidências de inflamação. $\mathrm{O}$ mesmo não foi observado no grupo controle, cujas feridas permaneciam com aspecto macroscópico semelhante ao observado no terceiro dia, com crosta espessa e presença de exsudato purulento em três animais.

Em relação à área lesionada, ocorreu contração das feridas ao longo do tempo e no décimo quarto dia pós-operatório essa área apresentava médias de $0,376 \mathrm{~cm}^{2}$ no grupo controle e de $0,045 \mathrm{~cm}^{2}$ 
Tabela 1 - Valores médios (desvios-padrão) da mensuração dos halos da atividade antibacteriana in vitro do óleo de buriti (Mauritia flexuosa).

\begin{tabular}{|c|c|c|}
\hline \multirow[b]{2}{*}{ Microrganismo } & \multicolumn{2}{|c|}{$\begin{array}{l}\text { Diâmetro do halo de inibição } \\
(\mathrm{mm})\end{array}$} \\
\hline & Óleo de buriti & Antibiótico \\
\hline Enterobacter aerogenes & $8,7 \pm 0,3^{\mathrm{c}, \mathrm{y}}$ & $23,5 \pm 0,1^{\mathrm{a}, \mathrm{x}}$ \\
\hline Staphylococcus aureus & $11,1 \pm 1,6^{\mathrm{b}, \mathrm{y}}$ & $24,5 \pm 0,7^{\mathrm{a}, \mathrm{x}}$ \\
\hline Bacillus subtilis & $16,5 \pm 0,1^{\mathrm{a}, \mathrm{y}}$ & $23,0 \pm 0,1^{\mathrm{a}, \mathrm{x}}$ \\
\hline Klebsiella pneumoniae & $15,0 \pm 0,1^{\mathrm{a}, \mathrm{y}}$ & $24,0 \pm 0,1^{\mathrm{a}, \mathrm{x}}$ \\
\hline Escherichia coli & - & $24,0 \pm 0,1^{\mathrm{a}}$ \\
\hline
\end{tabular}

Letras diferentes $(x-y)$ na mesma linha e (a-b-c) na mesma coluna são diferentes (Teste Duncan, $\mathrm{P}<0,05)$.

no grupo tratado. No referido período, as feridas presentes nos animais do grupo controle apresentavam percentual de contração de 52,0\%, enquanto que, no grupo tratado com óleo de buriti, o percentual de contração foi de $98,15 \%$. As mensurações foram realizadas até o décimo quarto dia pós-operatório, pois após este dia as feridas tratadas com óleo de buriti encontravam-se cicatrizadas, enquanto que as feridas dos animais do grupo controle apresentavam menor percentual de contração, não havendo, portanto, resolução da cicatrização. O percentual de contraçãoé um parâmetro morfométrico frequentemente utilizado como indicador de resolução do processo cicatricial (BATISTA et al., 2010). Esse fenômeno ocorre devido à diferenciação dos fibroblastos em miofibroblastos que apresentam capacidade contrátil e promovem força de tensão e união dos bordos da ferida (OLIVEIRA et al., 2010).

$\mathrm{Na}$ avaliação histológica dos fragmentos de tecido, verificou-se, no terceiro dia, em todos os animais de ambos os grupos, controle e o tratado com óleo de buriti, presença de crosta sobre a ferida composta por hemácias, fibrina, detritos celulares e células polimorfonucleares (Figura 1A). Avaliando-se a densidade das células leucocitárias, foi possível observar no grupo controle que a contagem de células

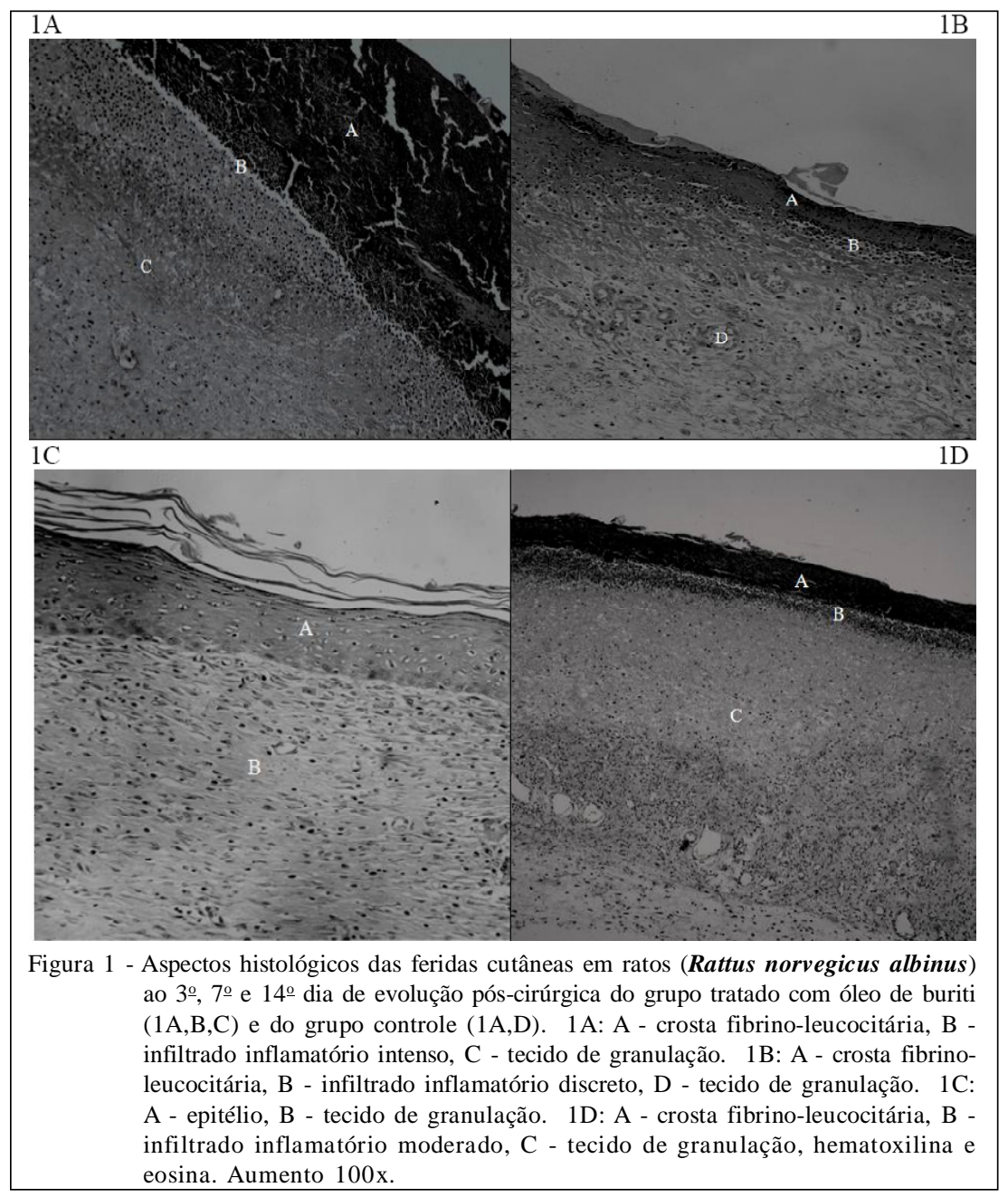

Ciência Rural, v.42, n.1, jan, 2012. 
polimorfonucleares diferiu significativamente $(\mathrm{P}<0,05)$ do grupo tratado no terceiro dia (Figura 1B). A densidade de células polimorfonucleares permaneceu alta no grupo controle nas avaliações subsequentes, indicando persistência do processo inflamatório agudo. No grupo tratado com óleo de buriti, no sétimo dia, constatou-se presença de fina crosta fibrinoleucocitária, discreto infiltrado inflamatório, além de tecido de granulação sobre as feridas (Figura 1B). Com relação à avaliação da densidade de vasos sanguíneos e macrófagos, no referido período, não se observou diferença estatística $(\mathrm{P}>0,05)$ entre os grupos (Tabela 2).

No décimo quarto dia, observou-se redução significativa $(\mathrm{P}<0,05)$ da contagem dos macrófagos no grupo tratado com o óleo, bem como não se constatou a presença de vasos sanguíneos no referido grupo (Tabela 2). Além disso, a análise da densidade dos componentes histológicos também demonstrou que, no décimo quarto dia, nas feridas dos animais dos grupos tratados com óleo de buriti, houve aumento significativo $(\mathrm{P}<0,05)$ na contagem de fibroblastos e fibras colágenas, além de completo processo de reepitelização (Figura 1C), no entanto, o grupo controle requereu mais tempo para cicatrizar (Figura 1D).

Outro dado importante refere-se à intensidade da inflamação observada nos exames macroscópicos e histológicos das feridas nos animais do grupo tratado com óleo de buriti. O processo inflamatório promove a exsudação de células leucocitárias que fagocitam e destroem agentes lesivos, restos tissulares e tecido necrótico, sendo portando a inflamação necessária para a boa resposta da reparação tecidual (MANDELBAUM et al., 2003). Entretanto, reação inflamatória intensa pode prejudicar o processo de reparo por promover edema, quantidade excessiva de exsudato, os quais favorecem deiscência, crescimento bacteriano e, consequentemente, a inibição da proliferação de fibroblastos e da deposição de colágeno (COTRAN et al., 2005).

No óleo essencial obtido da polpa dos frutos do gênero Mauritia, estão presentes substâncias descritas na literatura como capazes de promover efeito benéfico no processo de cicatrização. $\mathrm{O}$ óleo extraído da polpa do fruto de $\boldsymbol{M}$. flexuosa apresenta expressivas quantidades de carotenoides, vitamina E (a-tocoferol), ácidos graxos insaturados como o ácido oleico e linoleico (ALBUQUERQUE et al., 2005).

Os carotenoides e a vitamina $\mathrm{E}$ na forma de a-tocoferol apresentam efeito benéfico no processo de reparação tecidual por ligarem-se aos radicais livres produzidos no ferimento e, assim, proteger a membrana celular da peroxidação lipídica e conferir proteção à pele (MARTINS et al., 2008; PIANOVSKI et al., 2008). Em conjunto, compostos antioxidantes, como betacarotenoide e vitamina E exercem efeito protetor sobre as novas células a se formarem na lesão em regeneração. Por outro lado, as altas concentrações de ácidos graxos insaturados têm importante papel na regeneração tecidual, sendo um importante elemento para a formação e deposição das fibras colágenas sobre a cicatriz, além de promover a estimulação e proliferação celular (SANTOS et al., 2009).

O potencial medicinal das espécies do cerrado brasileiro, como o buriti, passa, primeiramente, pelo processo de resgate de informações, identificação botânica da espécie, investigação e a experimentação

Tabela 2 - Média e desvio padrão da densidade de neutrófilos, macrófagos, vasos sanguíneos, fibroblastos e fibras colágenas das feridas cutâneas de ratos no $3^{\circ}, 7^{\circ}$ e $14^{\circ}$ dia do grupo I óleo de buriti e grupo II controle.

\begin{tabular}{lllll}
\hline $\begin{array}{l}\text { Parâmetros } \\
\text { histológicos }\end{array}$ & Tempo & & & P-valor( ${ }^{1}$ ) \\
\hline \multirow{2}{*}{ Neutrófilo } & 3 dias & $49365,40 \pm 21668,10$ & $219021,8 \pm 69107,14$ & 0,001 \\
& 7 dias & - & $99385,00 \pm 34222,71$ & - \\
Vasos & 14 dias & - & $57456,20 \pm 43273,44$ & - \\
& 3 dias & - & $7,60 \pm 5,32$ & - \\
Macrófago & 7 dias & $14,80 \pm 4,32$ & $9,40 \pm 7,60$ & 0,205 \\
\multirow{2}{*}{ Fibroblastos } & 14 dias & $3,80 \pm 8,50$ & $3,20 \pm 1,10$ & 0,883 \\
\multirow{2}{*}{ Colágeno } & 7 dias & $71429,0 \pm 13,513,58$ & $104052,40 \pm 34840,71$ & 0,087 \\
& 14 dias & $14204,00 \pm 14564,92$ & $63517,80 \pm 52521,91$ & 0,104 \\
& 7 dias & $172525,80 \pm 47099,41$ & - & - \\
& 14 dias & $231722,60 \pm 88217,14$ & $39469,60 \pm 28488,57$ & 0,002 \\
\hline
\end{tabular}

${ }^{1} \mathrm{P}$-valor do teste $\mathrm{t}$ de Student para amostras independentes. 
como base para a obtenção de um produto fitoterápico eficiente, acessível e de baixo custo, útil ao emprego no homem e nos animais.

\section{CONCLUSÃO}

Os resultados obtidos neste estudo permitem concluir que o óleo do fruto de M. flexuosa mostrou-se eficiente no processo cicatricial de feridas cutâneas em ratos Wistar, uma vez que promoveu um maior percentual de contração dos bordos da ferida e foi estatisticamente significante na contagem de fibroblastos e fibras colágenas no grupo tratado com óleo de buriti em relação ao grupo controle, além de atividade antibacteriana in vitro tanto em bactérias gram positivas como em gram negativas.

\section{REFERÊNCIAS}

ALBUQUERQUE, M.L.S. et al. Characterization of buriti (Mauritia flexuosa L.) oil by absorption and emission spectroscopies. Journal of the Brazilian Chemical Society, v.16, n.6a, p.1113-1117, 2005. Disponível em: <http:// www.scielo.br/pdf/jbchs/v16n6a/27053.pdf>. Acesso em: 01 set. 2011. doi.org/10.1590/S0103-50532005000700004.

ALMEIDA, S.P. et al. Cerrado: espécies vegetais úteis. Planaltina: EMBRAPA-CPAC, 1998. 464p.

BATISTA, J.S. et al. Avaliação da atividade cicatrizante do óleo de pequi (Caryocar coriaceum wittm) em feridas cutâneas produzidas experimentalmente em ratos. Arquivo do Instituto Biológico, v.77, n.3, p.441-447, 2010. Disponível em: <http:/ /www.biologico.sp.gov.br/docs/arq/v77_3/batista.pdf $>$. Acesso em: 03 set. 2011.

COTRAN, R.S. et al. Robbins: patologia funcional e estrutural. 6.ed. Rio de Janeiro: Guanabara Koogan, 2000. $1252 \mathrm{p}$.

LIMA, M.R.F. et al. The antibiotic activity of some Brazilian medicinal plants. Brazilian Journal of Pharmacognos, v.16, n.3, p.300-306, 2006. Disponível em: <http:// www.scielo.br/pdf/rbfar/v16n3/a04v16n3.pdf>. Acesso em: 01 set. 2011. doi.org/10.1590/S0102-695X2006000300003.

MANDELBAUM, S.H. et al. Cicatrization: current and auxiliary resources - Part 1. Anais Brasileiros de Dermatologia, v.78, n.4, p.393-410, 2003. Disponível em: <http://www.scielo.br/ pdf/abd/v78n4/16896.pdf>. Acesso em: 01 set. 2011. doi.org/ $10.1590 / \mathrm{S} 0365-05962003000400002$.

MARTINS, M.L. et al. Ração suplementada com vitaminas C e E: influencia a resposta inflamatória aguda em tilápia do Nilo. Ciência Rural, v.38, n.1, p.213-218, 2008. Disponível em: <http://www.scielo.br/pdf/cr/v38n1/a34v38n1.pdf>. Acesso em: 01 set. 2011. doi.org/10.1590/S0103-84782008000100034.

OLIVEIRA, A.F. et al. Avaliação da atividade cicatrizante do jucá (Caesalpinia ferrea Mart. ex Tul. var. ferrea) em lesões cutâneas de caprinos. Revista Brasileira de Plantas Medicinais, v.12, n.3, p.302-310, 2010. Disponível em: $<\mathrm{http}$ ://www.ibb.unesp.br/servicos/publicacoes/rbpm/ pdf_v12_n3_2010/07_08_14.pdf>. Acesso em: 03 set. 2011. doi.org/10.1590/S1516-05722010000300007.
OLIVEIRA, G.F. et al. Antimicrobial activity of Syzygium cumini (Myrtaceae) leaves extract. Brazilian Journal of Microbiology, v.38, p.381-384, 2007. Disponível em: <http:/ /www.scielo.br/pdf/bjm/v38n2/v38n2a35.pdf >. Acesso em: 01 set. 2011. doi.org/10.1590/S1517-83822007000200035.

PELISSARI, G.P. et al. Atividade antibacteriana do óleo essencial de Melampodium divaricatum (Rich.) DC., Asteraceae. Brazilian Journal of Pharmacognosy, v.20, n.1, p.70-74, 2010. Disponível em: <http://www.scielo.br/pdf/rbfar/v20n1/ v20n1a15.pdf>. Acesso em: 01 set. 2011. doi.org/10.1590/ S0102-695X2010000100015.

PIANOVSKI, A.R. et al. Uso do óleo de pequi (Caryocar brasiliensis) em emulsões cosméticas: desenvolvimento e avaliação da estabilidade física. Brazilian Journal of Pharmaceutical Sciences, v.44, n.2, p.249-259, 2008. Disponível em: 〈http://www.scielo.br/pdf/rbcf/v44n2/a10.pdf>. Acesso em: 01 set. 2011. doi.org/10.1590/S151693322008000200010 .

PRATA, M.B. et al. Uso tópico do açúcar em ferida cutânea: estudo experimental em ratos. Acta Cirúrgica Brasileira, v.3, n.2, p.43-48, 1988.

RAMSEY, D.T. et al. Effects of three occlusive dressing materials on healing of full thickness skin wounds in dogs. American Journal of Veterinary Research, v.56, n.7, p.941-949, 1995.

ROSSO, V.V.; MERCADANTE, A.Z. Identification and quantification of carotenoids, by HPLC-PDA-MS/MS, from Amazonian fruits. Journal of Agricultural and Food Chemistry, v.55, p.5062-5072, 2007. Disponível em: <http:/ /pubs.acs.org/doi/pdfplus/10.1021/jf0705421>. Acesso em: 03 set. 2011. doi: $10.1021 / \mathrm{jf0705421.}$

SANTOS, J.S. et al. A Rosa Mosqueta no tratamento de feridas abertas: uma revisão. Revista Brasileira de Enfermagem, v.62, n.3, p.457-62, 2009. Disponível em: <http://www.scielo.br/ pdf/reben/v62n3/20.pdf>. Acesso em: 03 set. 2011.

SILVEIRA, C.S. et al. Atividade antimicrobiana dos frutos de Syagrus oleracea e Mauritia vinifera. Brazilian Journal of Pharmacognosy, v.15, n.2, p.143-148, 2005. Disponível em: 〈http://www.scielo.br/pdf/rbfar/v15n2/v15n2a13.pdf〉. Acesso em: 01 set. 2011. doi.org/10.1590/S0102695X2005000200012.

URZUA, A. et al. Antimicrobial study of the resinous exudate and of diterpenoids isolated from Eupatorium salvia (Asteraceae). Journal of Ethnopharmacology, v.46, p.3147, 1998. Disponível em: <http://www.sciencedirect.com/ science/article/pii/S0378874198000683>. Acesso em: 01 set. 2011. doi:10.1016/S0378-8741(98)00068-3.

ZANATTA, C.F. et al. Low cytotoxicity of creams and lotions formulated with buriti oil (Mauritia flexuosa) assessed by the neutral red release test. Food and Chemical Toxicology, v.46, p.2776-2781, 2008. Disponível em: <http:// www.sciencedirect.com/science/article/pi / S0278691508002238>. Acesso em: 01 set. 2011. doi:10.1016/ j.fct.2008.05.001.

ZANATTA, C.F. et al. Photoprotective potential of emulsions formulated with Buriti oil (Mauritia flexuosa) against UV irradiation on keratinocytes and fibroblasts cell lines. Food and Chemical Toxicology, v.48, p.70-75, 2010. Disponível em: <http://www.sciencedirect.com/science/article/pii/ S0278691509004256>. Acesso em: 01 set. 2011. doi:10.1016/ j.fct.2009.09.017. 